\title{
QUASI-3D MODELLING OF SURF ZONE DYNAMICS
}

\author{
A.P. Luijendijk ${ }^{1}$, J. Henrotte ${ }^{2}$, D.J.R. Walstra ${ }^{1,3}$, M. van Ormondt ${ }^{4}$
}

\begin{abstract}
A quasi-three-dimensional model (quasi-3D) has been developed through the implementation of an analytical 1DV flow model in existing depth-averaged shallow water equations. The model includes the effects of waves and wind on the vertical distribution of the horizontal velocities. Comparisons with data from both physical and field cases show that the quasi-3D approach is able to combine the effect of vertical structures with the efficiency of depth-averaged simulations. Inter-comparisons with three-dimensional simulations show that the quasi-3D approach can represent similar velocity profiles in the surf zone. Quasi-3D morphodynamic simulations show that the bed dynamics in the surf zone represent the relevant 3D effects in the surf zone much more than the depth-averaged computations. It was shown that the quasi-3D approach is computationally efficient as it only adds about $15-20 \%$ to the runtimes of a $2 \mathrm{DH}$ simulation which is minor compared to a run time increase of $250-800 \%$ when switching to a 3D simulation.
\end{abstract}

Keywords: quasi-3d modeling; surf zone modeling; nearshore morphodynamics;

\section{INTRODUCTION}

Over the last decade, process-based area models have become one of the major tools in coastal engineering. From relatively simple initial sedimentation-erosion estimates, process-based models are now being used to study morphodynamic behavior over increasing time scales. Especially in the coastal zone, the practical forecast horizon is limited as often three-dimensional (3D) simulations are required when cross-shore processes dominate over longshore processes (see e.g. Ruggiero et al., 2009). Quasi-3D approaches have been developed which primarily focused on improving the sediment transport predictions (Ranasinghe et al., 1999) without fully describing the vertical velocity profile. However, state-of-the-art sediment transport formulations require flow velocities over the complete water column to provide sufficiently accurate sediment transport estimates.

\section{PROBLEM DEFINITION}

When considering the depth-averaged current field to be representative of the entire velocity pattern, one makes the implicit assumption of vertical similarity of the velocity profile, i.e. the velocity profile in every point in the horizontal has the same shape (e.g. logarithmic). In reality, however, the velocity field is more complex. Such as in nearshore areas where breaking waves cause (secondary) return flow currents. In the breaker zone, the cross-shore velocity profile can exhibit a strong vertical shear. Where in the top layer the flow is directed onshore due to wave breaking, the bottom layers exhibit an offshore-directed return flow (see Figure 1).

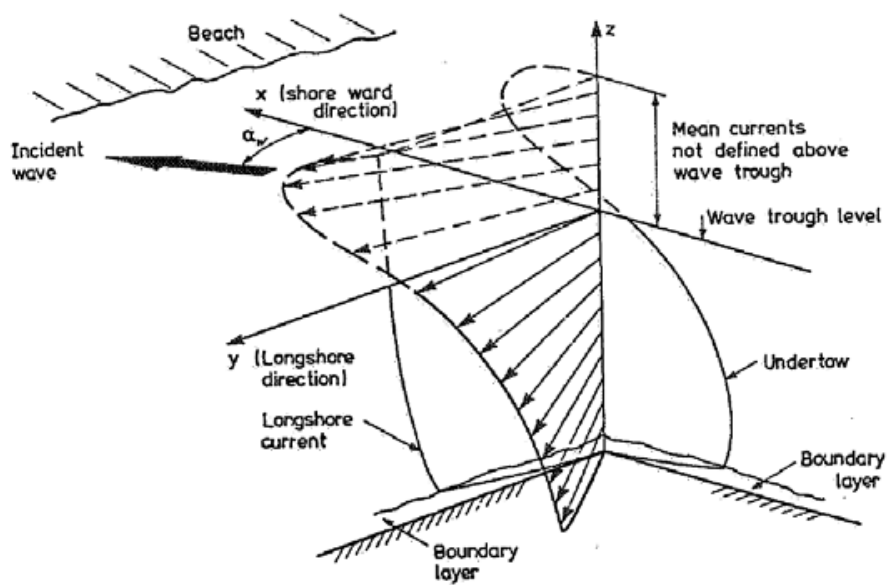

Figure 1. Three-dimensional structure of the velocities in the surf zone (from Svendsen \& Lorenz, 1989)

\footnotetext{
${ }^{1}$ Hydraulic Engineering, Deltares, Rotterdamseweg 185, 2629 HD, Delft, The Netherlands

${ }^{2}$ River and Coastal Engineering, DHV, Amersfoort, The Netherlands

${ }^{3}$ Hydraulic Engineering, Delft University of Technology, Stevinweg 1, $2628 \mathrm{CN}$, Delft, The Netherlands

${ }^{4}$ Marine \& Coastal Systems, Deltares, Rotterdamseweg 185, 2629 HD, Delft, The Netherlands
} 
The cross-shore currents, though usually rather weak compared to the maximum tidal and wave-driven longshore currents, but have a significant residual effect on the cross-shore sediment transports and bed dynamics. So, for an accurate description of the cross-shore components of sediment transport, current-, wind- and wave-related components have to be taken into account.

As depth-averaged computations do not resolve the 3D effects in the surf zone, like e.g. undertow, the balance between offshore and onshore-directed transports is not accurately solved. As a result, the development and evolution of breaker bars, largely governed by the delicate balance of wave asymmetry and skewness related onshore transport and undertow related off-shore transport, cannot be modeled accurately with a purely 2DH approach. Cross-shore profiles in depth-averaged computations typically have the tendency to flatten out. Of course, for accurate cross-shore profiles dynamics, threedimensional computations can be applied, but these simulations require (too) long computational times. In addition, a clear trend can be observed for the need to apply such computations over longer time scales and with more detailed representations.

The aforementioned aspects form the motivation for the implementation of a new approach within Delft3D. A quasi-3D approach has been implemented to represent 3D processes in a depth-averaged model, while keeping the additional computational time limited. This approach is hereafter referred to as the quasi-3D model. The quasi-3D model is an analytical point model based on Reniers et al. (2004), which computes the vertical velocity distribution at each grid point. The point model is also used in the profile model UNIBEST-TC (Ruessink et al., 2007).

\section{DESCRIPTION OF QUASI-3D MODEL}

The model of Reniers et al. (2004) is used to predict the vertical distribution of the cross-shore flow. The model is based on the concepts formulated by de Vriend and Stive (1987), defining a top layer above trough level, a middle layer and a bottom boundary layer (see Figure 2).

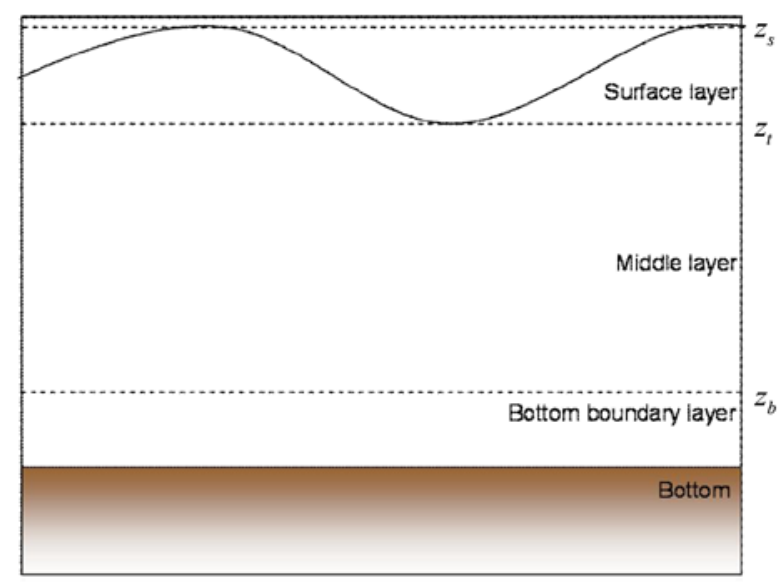

Figure 2. Vertical layers concept (de Vriend and Stive, 1987)

The bottom boundary layer represents the transition layer between the bed and the layer of 'normal' oscillating flow. The thickness of this layer depends on the roughness of the bed and the orbital excursion of the waves. The larger the waves, the larger the orbital excursion, and the larger the thickness of the bottom boundary layer. An increase of the roughness height also results in an increase of the bottom boundary layer thickness. A smooth bottom produces less friction, and less turbulence, resulting in a smaller wave boundary layer.

The vertical velocity distribution in both longshore and cross-shore are computed with the analytical point model (1DV), which is computationally very efficient. Details and formulations are discussed in Reniers et al. (2004). 
IMPLEMENTATION OF THE QUASI-3D MODEL IN DELFT3D

The quasi-3D model was developed in which the analytical 1DV flow model of Reniers et al. (2004) was coupled to the depth-averaged shallow water equations in which the effects of waves and wind on the vertical distribution of the horizontal velocities is accounted for (wave breaking induced currents, mass flux and boundary layer streaming). The quasi-3D velocities are used to calculate the local equilibrium sediment transport, $\mathrm{S}_{\mathrm{Q} 3 \mathrm{D}}$. The suspended sediment transports are calculated using a depthaveraged advection-diffusion equation.

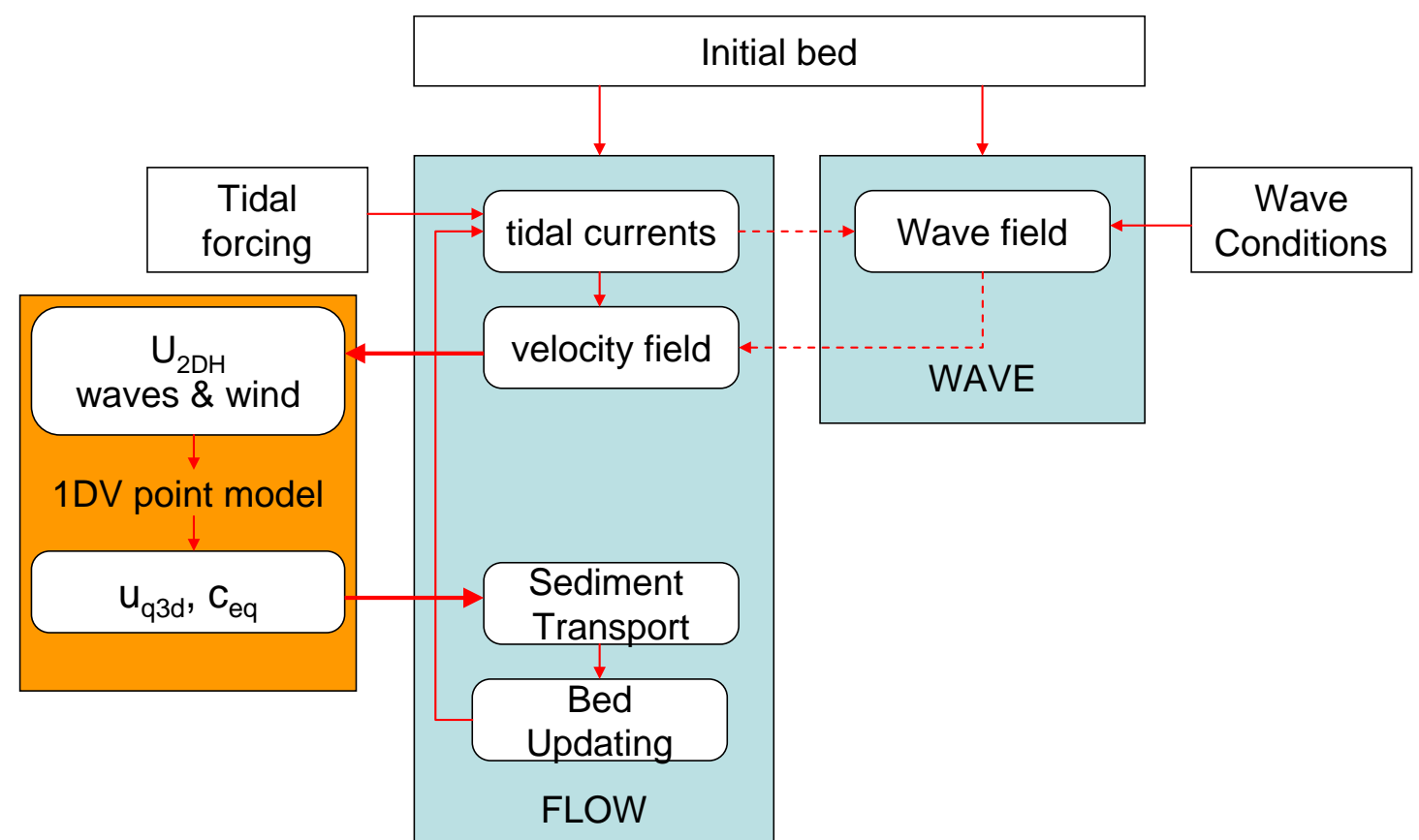

Figure 3. Graphical illustration of the Q3D implementation in the overall feedback loop in Delft3D.

The following section briefly explains some of the principal differences in numerical approach between sediment transport in 3D, 2D, and quasi-3D calculations.

In $3 \mathrm{D}$ calculations, the sediment source (erosion) term is calculated based on near-bed concentration gradients (determined with sediment reference concentration $c_{a}$ (Van Rijn, 2007) and computed concentration in layer above the bed) and near-bed vertical diffusivity (Lesser et al., 2004). The sink (deposition) term is computed by multiplying the near-bed suspended sediment concentration with the settling velocity. The actual sediment transport (both in horizontal and vertical direction) is computed by the 3D advection-diffusion solver. The vertical diffusivity that is applied typically comes from the $\mathrm{k}-\varepsilon$ model.

In 2DH calculations, a sub-grid approach (with 20 non-equidistant layers with higher resolution near the bed) is applied to compute the sediment profile over the vertical. Starting from the near-bed reference height, the concentrations are computed in each layer with a simple expression based on an upwind approximation for concentration and settling velocity, and central difference for the concentration gradient. The vertical diffusivity in this approach is computed with Van Rijn (2007). The vertical velocity profile is assumed to be logarithmic. The total suspended transport magnitude $S_{\text {sus,tot }}$ is then computed by integrating sediment concentration times velocity in each sub-grid layer over the vertical. The equilibrium concentration $\mathrm{C}_{\mathrm{eq}, 2 \mathrm{DH}}$ is computed as follows:

$$
\frac{S_{\text {sus }, \text { tot }}}{u_{\text {mag }} h}=c_{e q, 2 D H}
$$

where $\mathrm{u}_{\text {mag }}$ is the depth-averaged velocity magnitude and $h$ is the local water depth. 
Suspended load transport is computed by solving the depth-integrated advection-diffusion equation (Gallappatti, 1983).

$$
\frac{\partial h \bar{c}}{\partial t}+\bar{u} \frac{\partial h \bar{c}}{\partial x}+\bar{v} \frac{\partial h \bar{c}}{\partial y}-D_{H} \frac{\partial^{2} h \bar{c}}{\partial x^{2}}-D_{H} \frac{\partial^{2} h \bar{c}}{\partial y^{2}}=h \frac{\bar{c}_{e q, 2 D H}-\bar{c}}{T_{s}}
$$

where $\bar{C}$ is the depth-averaged concentration, $\bar{u}$ and $\bar{v}$ are the depth-averaged velocities in $\mathrm{x}$ and $\mathrm{y}$ direction, $\mathrm{D}_{\mathrm{H}}$ the horizontal diffusivity and $T_{\mathrm{s}}$ an adaptation time scale.

The new quasi-3D approach follows the standard 2DH approach, with four main differences.

1) The vertical concentration profile is computed with vertical diffusivity values taken from the 1DV model.

2) After the computation of the depth-averaged flow field, the vertical distribution of the mean current is computed in both $\mathrm{x}$ and $\mathrm{y}$ direction with the use of the quasi-3D method. Suspended transports $\mathrm{S}_{\mathrm{x}, \mathrm{q} 3 \mathrm{~d}}$ and $\mathrm{S}_{\mathrm{y}, \mathrm{q} 3 \mathrm{~d}}$ are computed, using the velocity distribution that follows from this approach (not the logarithmic current profile).

$$
\begin{aligned}
& \int_{z=a}^{z=z 1} u_{q 3 d}(z) c_{q 3 d}(z) d z=S_{x, q 3 d} \\
& \int_{z=a}^{z=z 1} v_{q 3 d}(z) C_{q 3 d}(z) d z=S_{y, q 3 d}
\end{aligned}
$$

where $a$ is the reference height above the bed (Van Rijn, 2007) and $z 1$ is the water surface. The depthaveraged equilibrium concentration in the quasi-3D model is then computed as:

$$
C_{e q, q 3 d, a v g}=\int_{z=a}^{z=z 1} \frac{C_{e q, q 3 d}(z) d z}{h}
$$

3) Bed load transports in u and v direction are computed with the near-bed currents that follow from the $1 \mathrm{DV}$ model.

4) Representative current velocities $u_{\text {rep }}$ and $v_{\text {rep }}$ (in the $x$ and $y$ directions respectively) are computed from the suspended transport vector, the actual depth-averaged equilibrium concentration $\mathrm{c}_{\mathrm{eq}, \mathrm{q} 3 \mathrm{~d}, \mathrm{avg}}$ and the local water depth:

$$
\begin{gathered}
\frac{S_{x, q 3 d}}{C_{e q, q 3 d, a v g} h}=u_{r e p} \\
\frac{S_{y, q 3 d}}{C_{e q, q 3 d, a v g} h}=v_{r e p}
\end{gathered}
$$

The representative current velocities are determined by assuming an equilibrium suspended sediment flux. With this approximation, the depth-integrated effect of the vertical distribution of the suspended transport is included. This approximation only holds if the vertical distribution of the actual concentration is similar to the vertical distribution of the equilibrium concentration. 
It is these velocities that are then fed to the advection-diffusion solver. Whereas, in the standard 2D approach, suspended transports are computed with actual depth-averaged currents and equilibrium concentrations, in the quasi-3D approach, they are calculated from representative currents and actual depth-averaged concentrations.

$$
\frac{\partial h \bar{c}}{\partial t}+\bar{u}_{\text {rep }} \frac{\partial h \bar{c}}{\partial x}+\bar{v}_{\text {rep }} \frac{\partial h \bar{c}}{\partial y}-D_{H} \frac{\partial^{2} h \bar{c}}{\partial x^{2}}-D_{H} \frac{\partial^{2} h \bar{c}}{\partial y^{2}}=h \frac{\bar{c}_{e q, q 3 d, a v g}-\bar{c}}{T_{s}}
$$

\section{Restrictions of the present implementation}

The presented implementation of the quasi-3D approach does not included density-driven currents. In addition, the quasi-3D velocities are not included in the bed shear stress formulations that are used in the hydrodynamic solver.

\section{HYDRODYNAMIC VALIDATION}

The performance of the hydrodynamics computed with the quasi-3D model is verified with two physical model experiments: the LIP experiments and the Reniers experiments. The first case focuses on cross-shore currents while for the latter case both the cross-shore and longshore currents are verified.

\section{LIP Experiment (1993)}

The LIP11D (Large Installation Plan) flume experiments were conducted in the $240 \mathrm{~m}$ long Delta flume at Deltares (Arcilla et al., 1994). Different wave conditions (erosive and accretive) were generated perpendicular to a barred beach and, meanwhile, wave height, water level, flow velocity profiles and concentration profiles were measured. Experiments were done for irregular waves approaching perpendicular to the coast, so only cross-shore circulation currents occurs (see Figure 4).

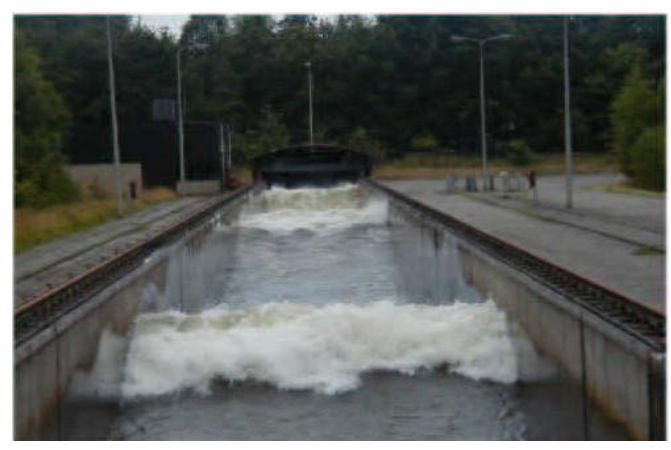

Figure 4. Photograph of the 240m long Delta Flume at Deltares

The cross-shore profile is presented in Figure 5 together with three measuring locations: A, B, and C. The wave transformation is well reproduced by the considered numerical models (see Fig. 6). Stationary model results computed with the quasi-3D model are compared with the results computed with the 2DH and fully 3D computation.

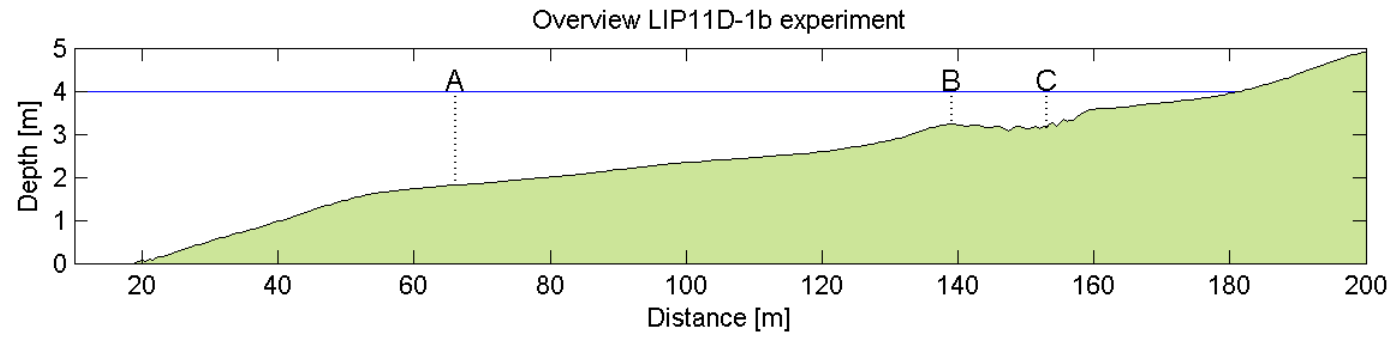

Figure 5. Initial bed level LIP11D-1b experiment including locations of vertical profiles 


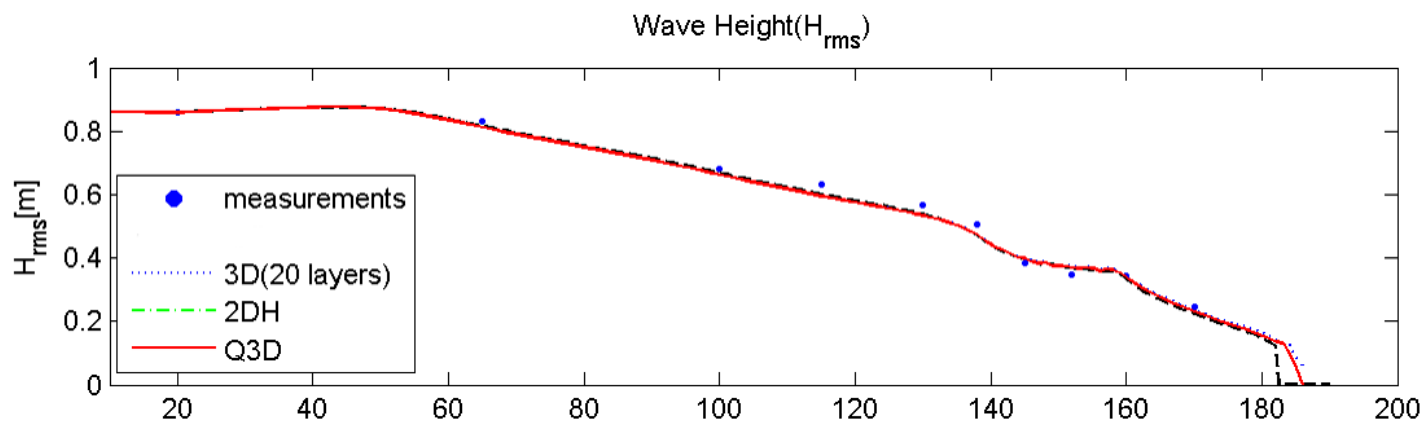

Figure 6. Computed wave heights for 3D, 2DH and quasi-3D model results compared with observations

Only small deviations between measured data and model results are observed. The different model approaches (2DH, 3D and quasi-3D) show almost no deviation for the wave heights results. However, the water levels are slightly higher in case of the 3D model (not presented), compared to the 2DH/ quasi-3D model results. This dissimilarity is mainly caused by the differences in bed shear stress between the $2 \mathrm{DH}$ and $3 \mathrm{D}$ model.
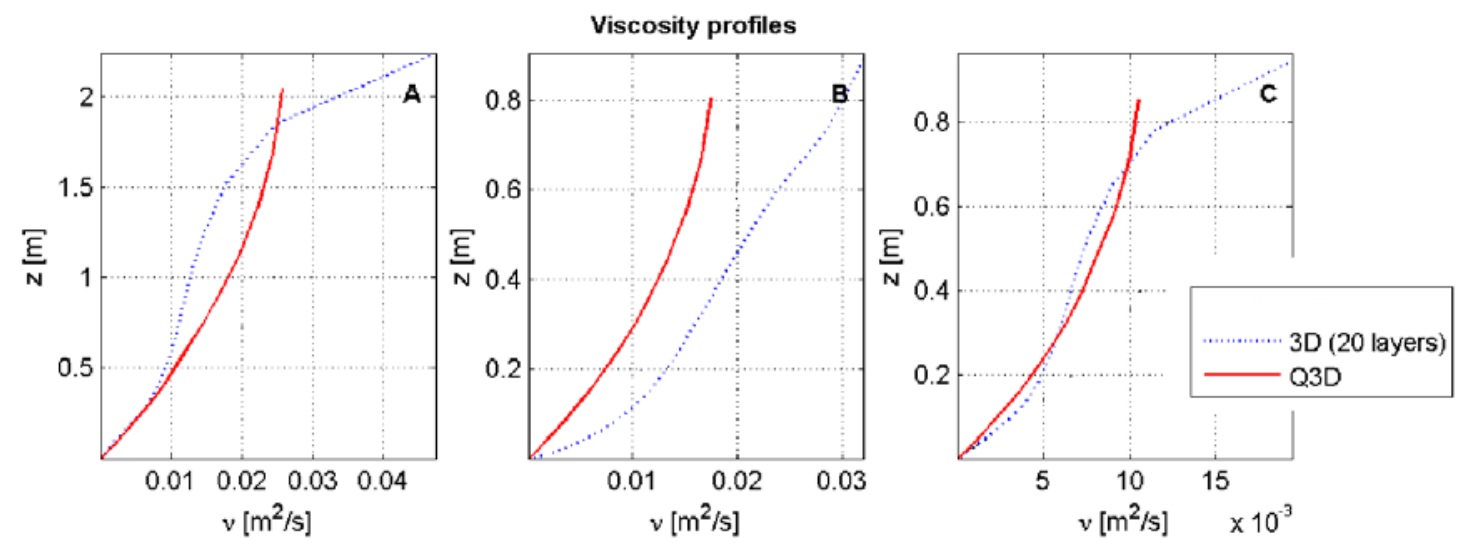

Figure 7. Computed viscosity profiles of 3D and quasi-3D model results for LIP experiment (see locations in Figure 5)

The computed viscosity profiles in the quasi-3D model correspond very well with 3D model results (see Fig. 7). Especially the magnitude of the viscosity profiles is comparable. However, the shape of both profiles show differences. These differences can be prescribed to the different turbulence closure models used to compute the viscosity profiles.
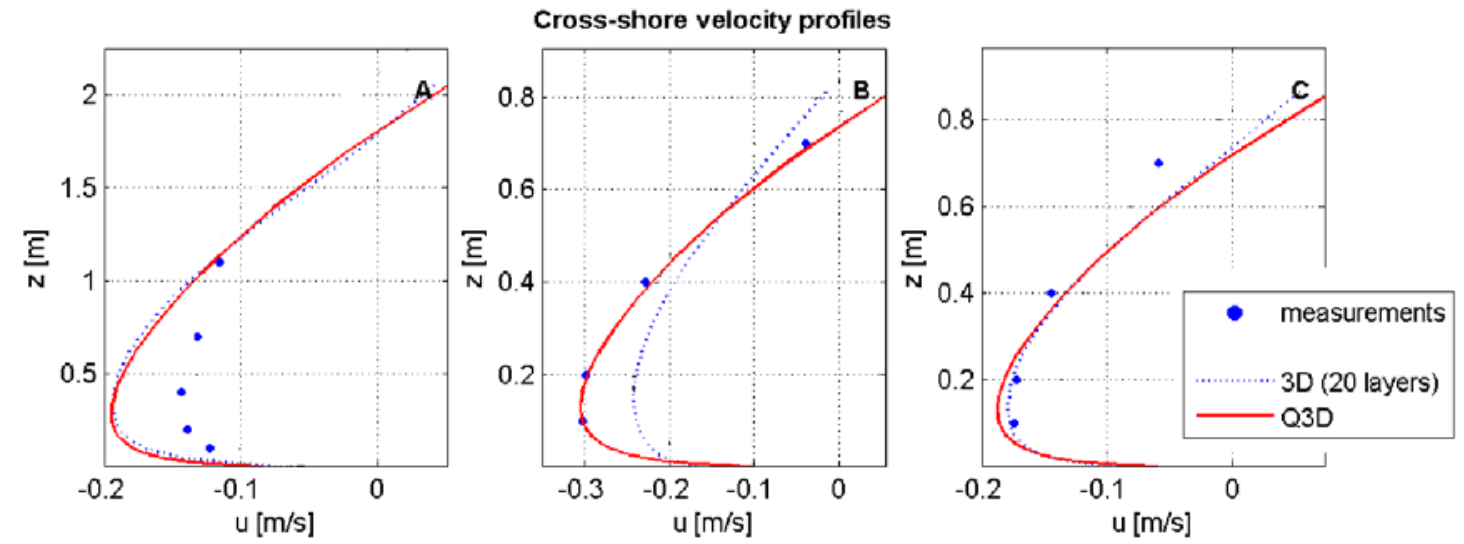

Figure 8. Cross-shore velocity profiles of 3D, and quasi-3D compared with observations for LIP experiment (see locations in Figure 5) 
The velocity distributions are compared in Figure 8. Results of quasi-3D and 3D model correspond fairly well. Only in the region of the breaker bar (profile B in Fig. 8), the quasi-3D results are overpredicted. This can be explained by the lower magnitude of viscosity of quasi-3D compared with 3D in this region. However, comparison with measured data shows a good fit of the model results for profile $\mathrm{B}$ and $\mathrm{C}$.

\section{Reniers Experiment (1995)}

After validation of the cross-shore hydrodynamics, the combined cross-shore and longshore hydrodynamics have been validated. As the current field in the quasi-3D model is identical to the $2 \mathrm{DH}$ approach, this section mainly shows the capability of reproducing measured longshore currents. The Reniers experiments were performed in a large basin with a pump recirculation system to create spatially homogeneous longshore currents. Unidirectional obliquely incident waves (regular and random) were used on barred and non-barred beaches to get information on wave transformation, setup of the mean water level and the cross-shore distribution of wave-driven longshore current velocity (see Figure 9). Hence, due to the oblique incident waves, cross-shore and longshore currents occur (see Figure 10).

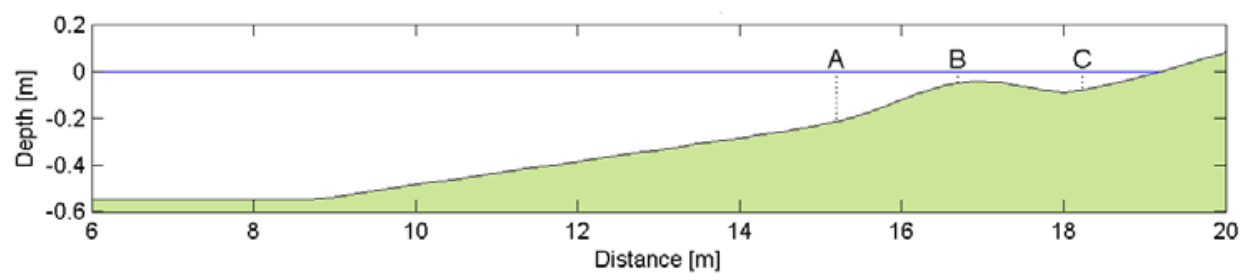

Figure 9. Initial bed level Reniers experiment including three locations of vertical profiles

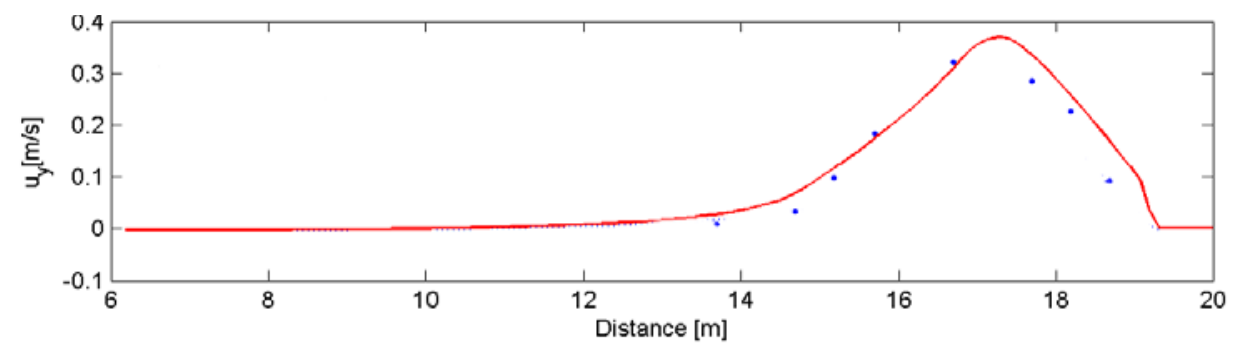

Figure 10. Computed depth-averaged longshore velocities vs. observations

The water level in the case of the 3D model is higher nearshore compared to the quasi-3D model (not presented). This is in line with the results from the LIP and Boers cases and can be attributed to the difference in the bottom shear stress between the 3D and 2DH/ quasi-3D approach. The computed longshore current correspond fairly well with the measured velocities (blue dots in Fig. 10).

\section{MORPHOLOGICAL VALIDATION}

This section discusses the sediment concentrations profiles, resulting sediment transports and morphodynamics. To validate the quasi-3D model several cases have been studied. In the present paper only one physical model experiment (LIP) and one field experiment (Egmond) are presented.

\section{LIP Experiment}

The computed concentration profiles with the quasi-3D model are comparable with the profiles computed with the 3D model (see Figure 11). In more shallow areas differences in computed velocities between the $3 \mathrm{D}$ and quasi-3D model cause some deviations in concentrations. 


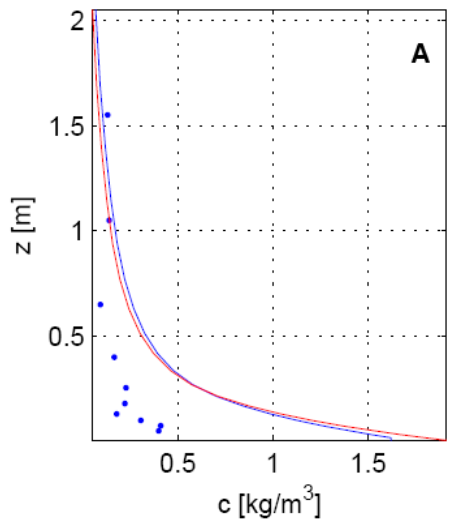

- Measurements

3D (20 layers)
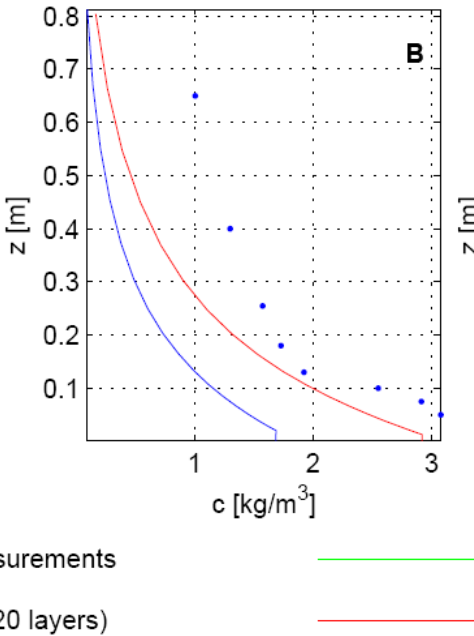

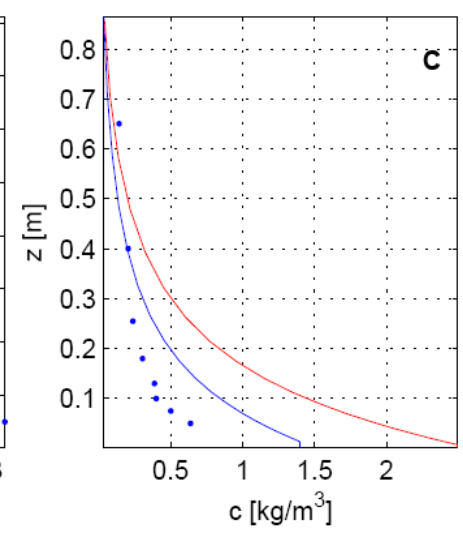

$2 \mathrm{DH}$

Q3D

Figure 11. Computed and measured concentration profiles at the three locations (see locations in Fig 5)

Summation of the bed load and suspended load results in the total sediment transport. Model results show especially around the breaker bar significant differences between 2DH, 3D and quasi-3D models (Figure 12). This is mainly caused by the difference in the suspended load due to currents.

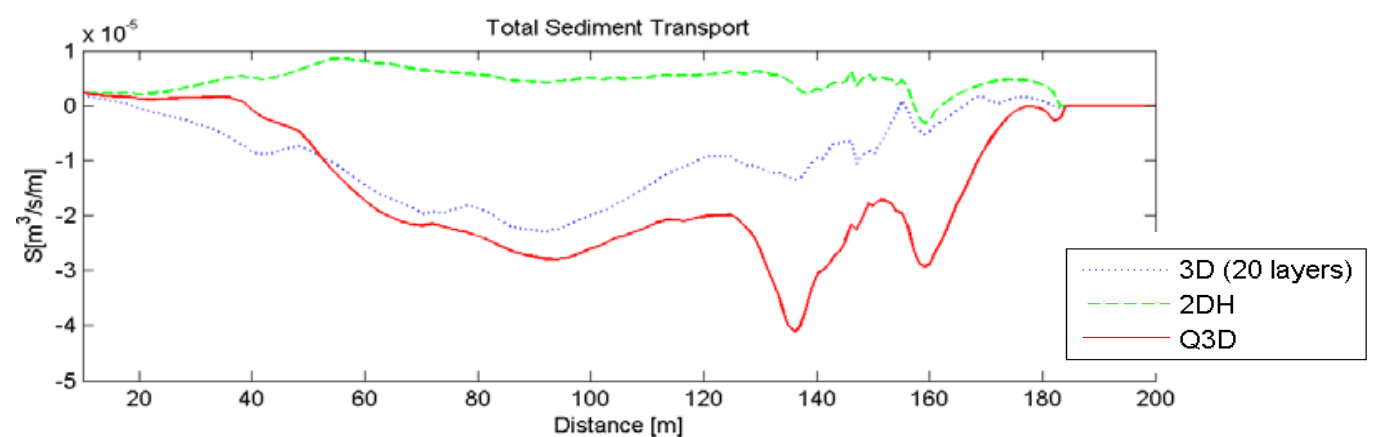

Figure 12. Computed total sediment transport with 3D, quasi-3D and 2DH model

\section{Egmond field case (1998)}

As a part of the Coast3D program, several measurements were carried out near the coast of Egmond, The Netherlands (Figure 13). The coast of Egmond is characterized by an alongshore uniform beach with no obstacles. Two breaker bars are located parallel to the coast. Several measurements were performed and also detailed boundary conditions like wind field, deep water wave height and water levels were obtained.

Quasi-3D longshore sediment transport rates show similarity with 3D longshore sediment transport

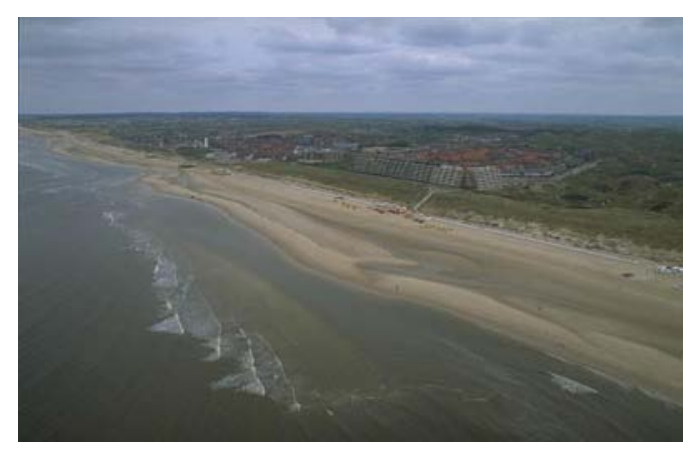

Figure 13. Coastal area near Egmond

rates during high tide. During low tide, these values differ in the vicinity of the outer breaker bar. This difference is mainly caused by the differences between 2DH/ quasi-3D and 3D depth-averaged velocities. 

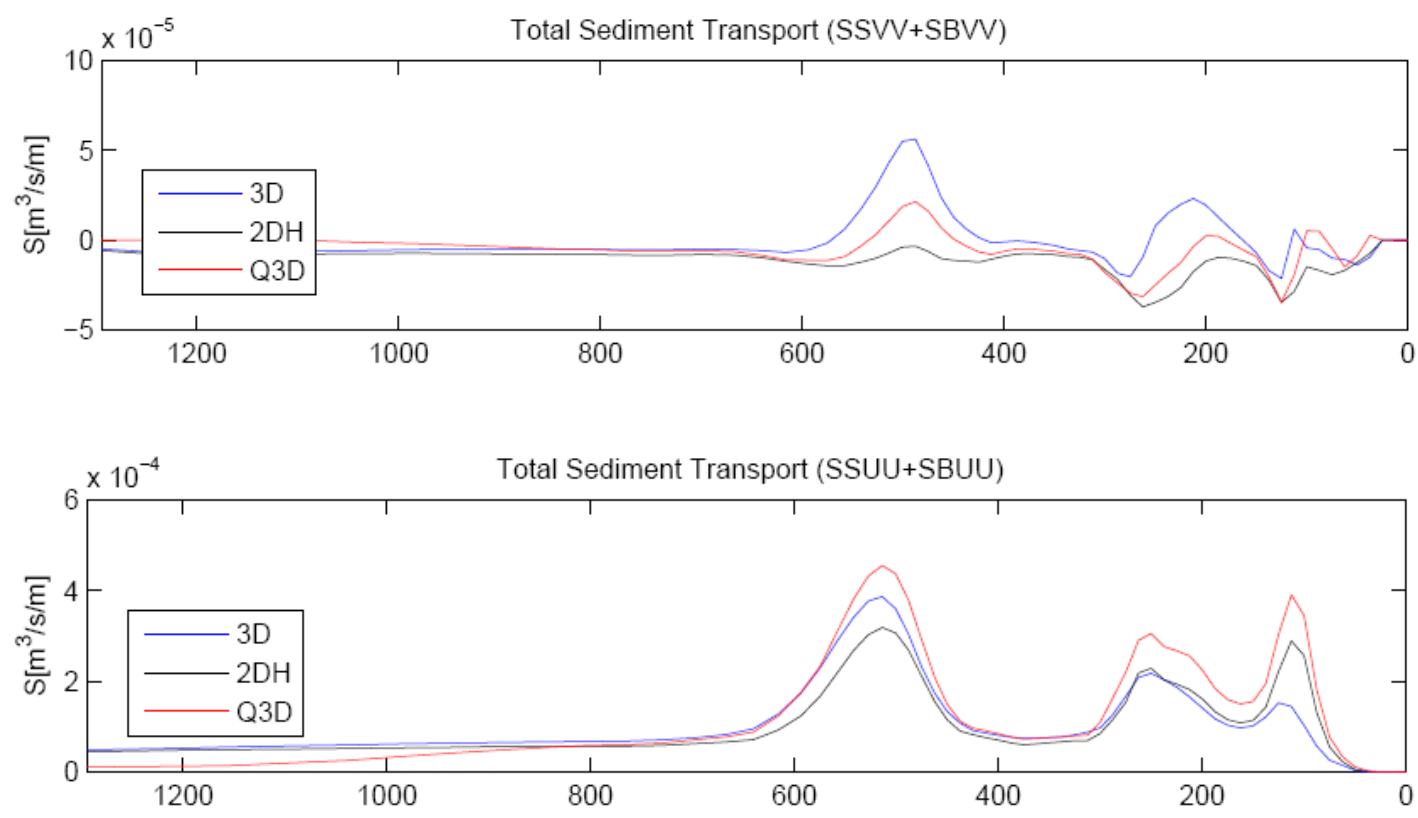

Figure 14. Computed total sediment transports in cross-shore (top panel) and longshore direction for 3D, quasi-3D and 2DH model for the Egmond case.

Cross-shore sediment transport rates show both during low tide and high tide an increase compared with 2DH sediment transport rates. However, 3D model results differ significantly with the quasi-3D model results. Again, this is mainly induced by the differences in depth-averaged velocities of $2 \mathrm{DH}$ and 3D model results. A slight overestimation of the longshore sediment transport can be observed in the quasi-3D modeling results.

The site at Egmond is characterized by a combination of tide and wave forcing. Therefore this case is modeled with a combination of tide and a time- and spatially varying wave field. This results in complex flow patterns which in reality includes both 2DH and 3D processes and velocities. Morphological computations have been conducted for the coastal area near Egmond. With a morphological scale factor of one (morfac $=1$ ), the bed level changes over one tidal cycle are computed and compared for 3D, 2DH, and quasi-3D model results. The results are presented in Figure 16; the yellow/red is sedimentation while blue represents erosion.

In Figure 15 the 3D model results (left panel) show a band of sedimentation at the offshore side of the outer breaker bar, caused by an offshore migration of the outer breaker bar in the 3D model. The depth-averaged modeling (2DH) shows mainly a migration of the bar in onshore direction, due to a.o. the lack of undertow and hence offshore transports in these computations. The erosion is less than in the 3D computation as no offshore bar migration occurs. The quasi-3D model results show a similar patterns as the 3D model. Especially the quasi-3D migration of the inner breaker bar corresponds very well with the result of the 3D model. 

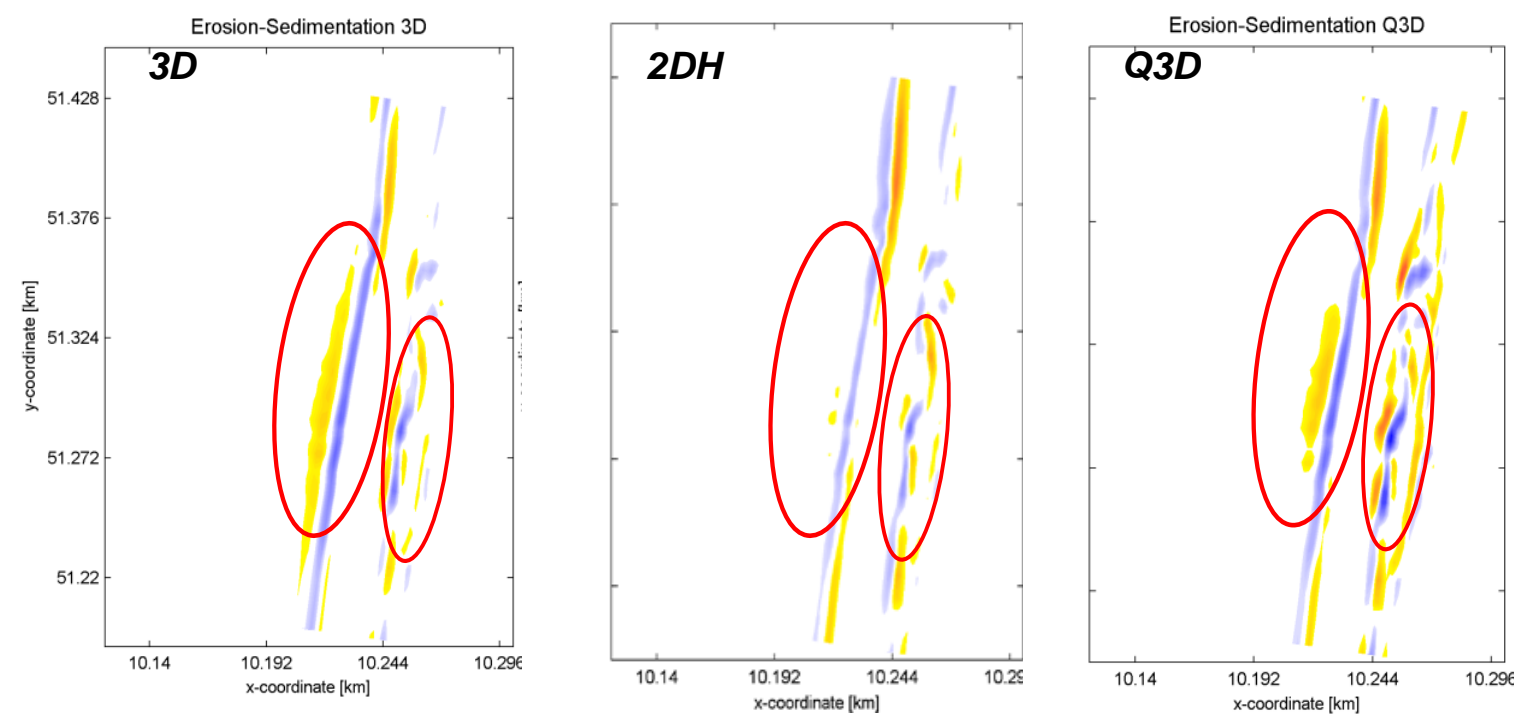

Figure 15. Computed erosion sedimentation patterns at Egmond. for 3D (left), 2DH (middle) and Q3D (right) model. The red circles indicate areas with significant

The outer breaker bar is partly represented very well (middle part), while the north and south parts of this bar showed more similarity with 2DH model results. The quasi-3D model results showed more detail at the inner breaker bar compared with 2DH and 3D model results. So, some areas threedimensional processes are more dominant, while in other areas the morphological development is governed by a combination of 2DH and 3D effects.

\section{EVALUATION OF COMPUTATIONAL EFFICIENCY}

One of the motivations to implement the quasi-3D method in Delft3D is to reduce the calculation time. This section compares the calculation time of the different approaches (2DH, 3D and quasi-3D). To compare the calculation times, the CPU-time of the different models are discussed. The times are divided in several parts to check the overhead time for each part of the model. The best value to make a comparison between the three different modes of Delft3D is the simulation time. This is defined as the calculation time from the first time step till the last time step.

As an example the Egmond case is considered, which is a field model meaning that the computations are done in two directions ( $\mathrm{u}$ - and v-direction). The simulation has an online coupling with the Delft3D-WAVE module (using SWAN). This results in an additional computational time for the wave calculation. Still a comparison can be made between the different models through comparing the CPU times. The CPU-times only takes the flow computations into account. When comparing the simulation CPU-times it can be seen that the quasi-3D model yields an increase time of less then 20\%. Table 1 depicts the CPU times for different modules of the simulation and also for the three different models (2DH, 3D and quasi-3D). 
Table 1. Overview of computational times for the Egmond case

\begin{tabular}{|c|c|c|c|c|c|c|}
\hline \multicolumn{7}{|c|}{ CPU Time (Egmond validation case) } \\
\hline \multirow[b]{2}{*}{ name } & \multicolumn{2}{|c|}{$2 \mathrm{DH}$} & \multicolumn{2}{|c|}{ 3D (20 layers) } & \multicolumn{2}{|c|}{$\overline{Q 3 D}$} \\
\hline & sec & $\%$ & sec & $\%$ & sec & $\%$ \\
\hline Initialization & 0,27 & 100 & 0,58 & 214,81 & 0,28 & 103,70 \\
\hline Simulation & 1810,58 & 100 & 12831,06 & 708,67 & 2157,53 & 119,16 \\
\hline Close and stop & 0,05 & 100 & 0,11 & 220,00 & 0,06 & 120,00 \\
\hline Total & 1810,9 & 100 & 12831,75 & 708,58 & 2157,87 & 119,16 \\
\hline Momentum equation & 45,64 & 100 & 2646,69 & 5799,06 & 45,50 & 99,69 \\
\hline Continuity & 42,81 & 100 & 1244,09 & 2906,07 & 43,97 & 102,71 \\
\hline Transport & 200,38 & 100 & 3082,53 & 1538,34 & 201,80 & 100,71 \\
\hline Turbulence & 1,31 & 100 & 2186,3 & 166893,13 & 1,52 & 116,03 \\
\hline 3D Morphology & 1239,27 & 100 & 2079,7 & 167,82 & 1582,88 & 127,73 \\
\hline Wait (dd module) & 0 & 100 & 0 & 100,00 & 0,00 & 100,00 \\
\hline Wait (ext. modules) & 0,08 & 100 & 0,12 & 150,00 & 0,09 & 112,50 \\
\hline
\end{tabular}

Based on the CPU times for five different applications (from 1D physical to 2D field cases) the computational times are illustrated in Figure 16. It is distinct that in all cases the 3D simulations require a factor 3 to 8 more CPU time than the depth-averaged simulations; so, up to $800 \%$. A very satisfying conclusions is that the quasi-3D simulations require only $20-25 \%$ additional CPU time compared to the depth-averaged simulations.

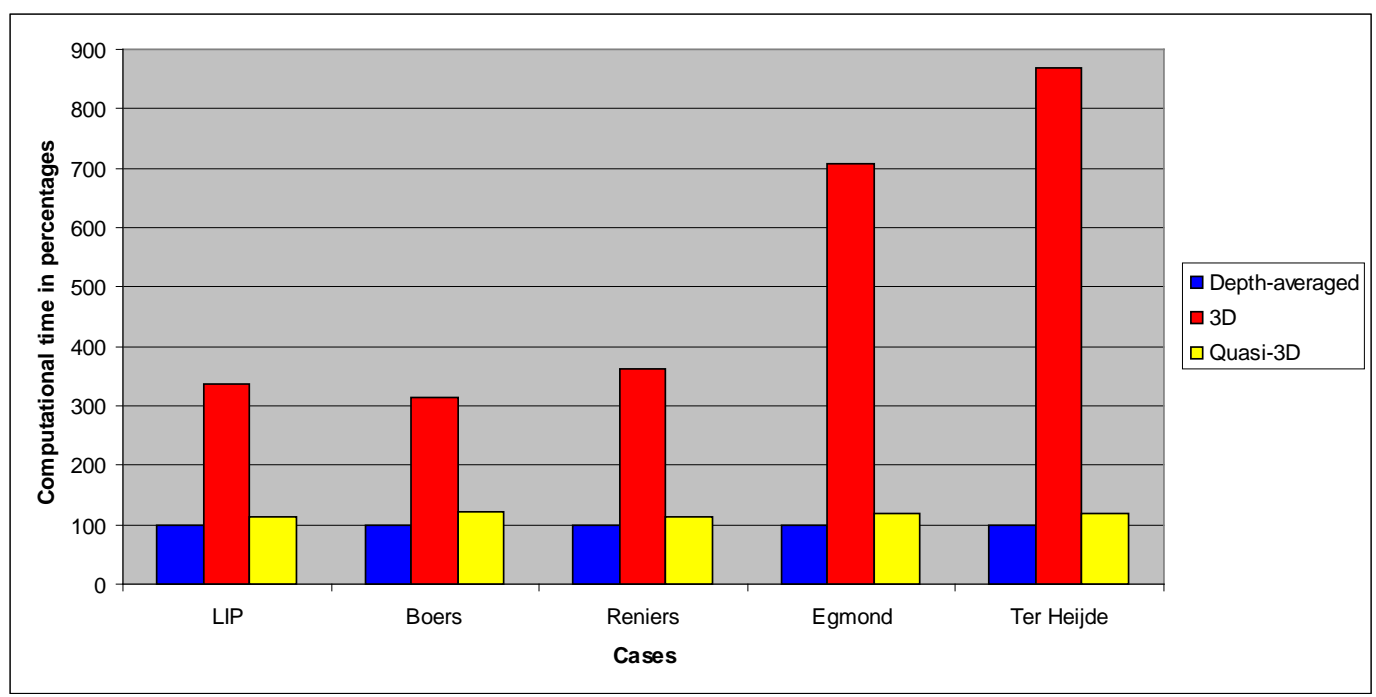

Figure 16. Overview of computational times for five applications for the three different models

\section{CONCLUSIONS}

A quasi-three-dimensional (quasi-3D) model based on the concepts of Reniers et al. (2004) has successfully been implemented into the Delft3D modeling software. This functionality enables the computation of the vertical velocity distribution taking into account tidal forcing, wave breaking, wind and dissipation due to bottom friction in a depth-averaged model.

Validation based on several cases (both physical and field) showed high agreement between quasi-3D model results and fully 3D model results, with the following findings:

Hydrodynamics: quasi-3D cross-shore velocity profiles show good agreement with 3D velocity profiles in both shape and magnitude. Longshore velocity profiles show similar logarithmic shaped profiles for both quasi-3D and 3D model results.

Sediment transport: quasi-3D equilibrium concentrations are higher compared with depth-averaged $(2 \mathrm{DH})$ concentrations. In combination with an increased reference velocity, the suspended transport rates are increased. This results in higher total sediment transport rates. 
Morphology: Profile models shows an increase in the migration of an offshore bar for quasi-3D modeling compared with 2DH and 3D. The quasi-3D erosion and sedimentation patterns show both 2DH and 3D effects

It was shown that the quasi-3D approach is very computational efficient as it only adds about $15-20 \%$ to the run times relative to a $2 \mathrm{DH}$ simulation which is minor compared to a run time increase of 250$800 \%$ when switching to a full 3D simulation.

\section{REFERENCES}

Arcilla, A.S., J.A. Roelvink, B.A O’Connor, A.J.H.M. Reniers, and J.A. Jimenez. 1994. The Delta Flume'93 experiments, Proc. Coastal Dynamics '94, Barcelona, Spain, ASCE, New York (1994), pp. 488-502.

De Vriend, H.J. and M.J.F. Stive. 1987. Quasi-3D modelling of nearshore currents. Coastal Engineering, 11, pp. 565-601.

Gallappatti, R. 1993. A depth integrated model for suspended transport, Delft Univ. Rep. 83-7, Department of Civil Engineering, Delft University of Technology, Delft, The Netherlands.

Lesser, G.R., J.A. Roelvink, J.A.T.M. van Kester, and G.S. Stelling, 2004. Development and validation of a three-dimensional morphological model. Coastal Engineering 51, pp. 883 - 915.

Ranasinghe, R., C. Pattiaratchi, G. Masselink. 1999. A morphodynamic model to simulate the seasonal closure of tidal inlets, Coastal Engineering, 37, Issue 1.

Reniers, A.J.H.M., E.B. Thornton, T.P. Stanton, and J.A. Roelvink. 2004. Vertical flow structure during Sandy Duck: observations and modeling. Coastal Engineering, 51, pp. 237-260.

Roelvink, J.A., and I. Broker. 1993. Cross-shore profile models. Coastal Engineering 21, 193- 224.

Roelvink, J.A., and A.J.H.M. Reniers. 1994. Upgrading of a quasi-3D hydrodynamic model, Abstractsin-depth, MAST G8-M overall workshop, Gregynog.

Ruessink B.G., Y. Kuriyama, A.J.H.M. Reniers, J.A. Roelvink and D.J.R. Walstra, 2007. Modeling cross-shore sandbar behavior on the time scale of weeks. Journal of Geophysical Research, 112

Ruggiero, P., D.J.R. Walstra, G. Gelfenbaum, and M. van Ormondt. 2009. Seasonal-scale nearshore morphological evolution: Field observations and numerical modelling Coastal Engineering, 56, Issues 11-12.

Stive, M.J.F. and H.G. Wind. 1986. Cross-shore mean flow in the surf zone. Coastal Engineering 10, 325-340.

Svendsen, I.A. and R.S. Lorenz, 1989. Velocities in combined undertow and longshore currents. Coastal Engineering, 13, pp 55-79

van Dongeren, A.R. and A. Svendsen. 1997. Quasi-3D modelling of nearshore hydrodynamics. Research Report No. CACR-97-04.

van Rijn, L.C., 2007. Unified View of Sediment Transport by Currents and Waves. I: Initiation of Motion, Bed Roughness, and Bed-Load Transport." Journal of Hydraulic Engineering, 133 